\title{
De effectiviteit van leefstijlinterventies in de eerste lijn
}

\begin{abstract}
Samenvatting
Lakerveld J, Bot SD, Nijpels G. De effectiviteit van leefstijlinterventies in de eerste lijn. Huisarts Wet 2014;57(2):64-7.

ACHTERGROND Uit gecontroleerd onderzoek is gebleken dat leefstijlinterventies effectief kunnen zijn in het kader van diabetespreventie. Of dezelfde resultaten ook in de eerste lijn haalbaar zijn, is onbekend. In het Leefstijl Onderzoek West-Friesland onderzochten we de (kosten)effectiviteit van interventies gericht op leefstijlveranderingen bij volwassenen met een verhoogd risico op diabetes mellitus type 2 (DM II) en hart- en vaatziekten (HVZ) in de huisartsenpraktijk.
\end{abstract}

METHODE We verdeelden 622 volwassenen met een risico van $10 \%$ of hoger op DM II en/of HVZ at random over een controle- en een interventiegroep, en volgden deze gedurende 24 maanden. De interventiegroep ( $n=314$ ) kreeg individuele counselinggesprekken op basis van motivational interviewing en problem solving treatment, uitgevoerd door praktijkondersteuners. De controlegroep ( $\mathrm{n}=$ 308) kreeg alleen informatiebrochures. Uitkomstmaten waren het geschatte risico op DM II en HVZ (ARIC- en SCORE-risicoformules), lichamelijke activiteit, voeding en rookgedrag.

RESULtATEN Aan de laatste meting namen 490 (79\%) deelnemers deel. Op geen van de vervolgmetingen vonden we verschillen tussen de groepen wat betreft DM II- of HVZ-risico of leefstijl.

Conclusie Zowel op de korte als de langere termijn maakte het voor het geschatte risico op DM II of HVZ en voor de leefstijl niet uit of de deelnemers het leefstijlprogramma kregen of alleen maar brochures. Verder onderzoek moet uitwijzen of leefstijlinterventies buiten de onderzoeksetting wel effectief kunnen zijn als deze behalve op individuele determinanten ook op omgevingsdeterminanten aangrijpen.

\section{INLEIDING}

$\mathrm{D}^{\mathrm{i}}$ iabetes mellitus type 2 (DM II) en hart- en vaatziekten (HVZ) worden voor een belangrijk deel veroorzaakt door een ongunstige leefstijl, zoals onvoldoende lichamelijke activiteit, roken en een ongezond voedingspatroon. Om het risico te verminderen zijn leefstijlveranderingen noodzakelijk. In toenemende mate verwachten beleidsmakers van zorgverleners dat zij vaststellen wie tot de risicogroepen behoren en effectieve interventies aanbieden om de noodzakelijke veranderingen te bewerkstelligen. Hooggecontroleerde onderzoeken (efficacy trials) hebben overtuigend aangetoond dat het mogelijk

VUmc, EMGO Instituut, afdeling Huisartsgeneeskunde en Ouderengeneeskunde, Van der Boechorststraat 7, 1081 BT Amsterdam: dr. J. Lakerveld, senior onderzoeker; dr. S.D. Bot, senior onderzoeker; prof.dr. G. Nijpels, hoogleraar huisartsgeneeskunde met speciale aandacht voor diabeteszorg • Correspondentie: j.lakerveld@vumc.nl • Mogelijke belangenverstrengeling: ZonMw heeft het Leefstijl Onderzoek West-Friesland gefinancierd.

Dit artikel is een bewerkte vertaling van: Lakerveld J, Bot SD, Chinapaw MJ, Van Tulder MW, Kostense PJ, Dekker JM, et al. Motivational interviewing and problem solving treatment to reduce type 2 diabetes and cardiovascular disease risk in real life: a randomized controlled trial. Int J Behav Nutr Phys Act 2013;10:47. Publicatie gebeurt met toestemming van de uitgever. is om het ontstaan van DM II bij volwassenen met een licht gestoorde glucosetolerantie uit te stellen door middel van een intensief leefstijlprogramma. ${ }^{1}$ Kenmerkend voor deze efficacy trials is dat de interventies 'onder laboratoriumomstandigheden' hebben plaatsgevonden: de deelnemers waren veelal niet uit de 'normale' bevolking afkomstig en het leefstijlprogramma werd in de onderzoeksetting gegeven. Hoewel het waardevol is om te weten dat het mogelijk is om met leefstijlveranderingen DM II en HVZ uit te stellen of zelfs te voorkomen, is het tot nu toe niet gelukt om deze gunstige resultaten te vertalen naar de praktijk. ${ }^{2}$ Praktische belemmeringen in het vertalen van deze interventies zijn de complexiteit en intensiviteit van de interventies, de grote hoeveelheid personen die men moet testen om mensen op te sporen met een licht gestoorde glucosetolerantie en de hoge kosten. De leefstijlinterventies die wel in de praktijk zijn geïmplementeerd en degelijk zijn onderzocht door middel van gerandomiseerde gecontroleerde onderzoeken laten wisselende resultaten zien. De meeste interventies blijken ineffectief en als ze in eerste instantie al effectief waren, dan doofden deze effecten snel weer uit. ${ }^{2}$ Er is grote behoefte aan (kosten)effectieve interventies om de ongunstige leefstijl van mensen met een verhoogd risico op DM II en HVZ te verbeteren. Daarom hebben we een innovatief en haalbaar leefstijlprogramma ontwikkeld, dat we hebben toegesneden op de praktijk van de huisarts. We hebben dit programma uitgevoerd in verschillende huisartsenpraktijken en

\section{Wat is bekend?}

- Leefstijlinterventies in hooggecontroleerde settings kunnen de diabetesincidentie bij personen met een verstoord glucosemetabolisme verlagen.

- Deze goede resultaten zijn (nog) niet gereproduceerd in de eerstelijnsgezondheidszorg.

- Een letterlijke vertaling van effectieve interventies naar de eerste lijn is geen optie omdat de daarvoor benodigde middelen en trainingsmogelijkheden veelal ontbreken.

\section{Wat is nieuw?}

- We hebben een innovatieve en haalbare leefstijlinterventie ontwikkeld en geïmplementeerd, die is afgestemd op de beschikbare middelen en de infrastructuur in de eerstelijnsgezondheidszorg.

- In het Leefstijl Onderzoek West-Friesland hebben we de effecten van deze leefstijlinterventie onderzocht, die specifiek gericht was op het verminderen van het risico op diabetes type 2 en hart- en vaatziekten.

- De bevindingen tonen aan dat deze vorm van primaire preventie niet effectiever is dan het verstrekken van informatiebrochures; het lijkt dan ook geen optimale interventie om mensen tot leefstijlverandering te brengen. 
onder voor de huisartsenpraktijk gangbare condities. De resultaten hebben we geëvalueerd in het kader van het Leefstijl Onderzoek West-Friesland. ${ }^{3}$

We hebben het onderzoek opgezet om de effectiviteit van een innovatief leefstijlprogramma te evalueren. De vraagstellingen luiden als volgt:

1. Wat zijn de effecten van het leefstijlprogramma op het geschatte negenjaarsrisico op DM II en het tienjaarsrisico op een fatale hart- of vaatziekte?

2. Wat zijn de effecten van het programma op het voedingspatroon, de lichamelijke activiteit en het rookgedrag?

3. Wat is de kosteneffectiviteit van het leefstijlprogramma?

\section{METHODE}

\section{Procedure/populatie}

We stuurden een informatiebrief en een meetlint naar 8193 mensen van 30 tot 50 jaar uit de regio West-Friesland. We vroegen hen om de middelomvang te meten en de antwoordkaart terug te zenden. Degenen onder hen met een vergrote middelomvang (vrouwen $>86 \mathrm{~cm}$ en mannen $>100 \mathrm{~cm}$ ) nodigden we uit om naar het Diabetes Centrum te komen voor het invullen van een gevalideerde vragenlijst over (determinanten van) leefstijl, ${ }^{4}$ het meten van lengte en gewicht, het bepalen van de bloeddruk, en het afnemen van bloed voor onderzoek naar lipiden, glucose en HbA1c. Met behulp van de ARIC- en de SCORE-predictiemodellen berekenden we voor iedereen het DM II- en HVZ-risico. De ARIC (Atherosclerosis Risk In Communities) formule is gebaseerd op etniciteit, het vóórkomen van diabetes bij een van de ouders, systolische bloeddruk, middelomvang en lengte. 5 De SCORE-formule (ontwikkeld in het kader van het Systematic COronary Risk Evaluation-project) is gebaseerd op geslacht, rookgedrag, totaal cholesterol en systolische bloeddruk. ${ }^{6}$ Alle deelnemers met meer dan 10\% risico op ten minste een van beide scores deelden we in op basis van randomisatie in de interventiegroep of de controlegroep.

De interventiegroep kreeg het leefstijlprogramma, dat bestaat uit een serie counselinggesprekken, die praktijkondersteuners $(\mathrm{POH})$ in de huisartsenpraktijken uitvoerden. De $\mathrm{POH}$ hadden hiervoor een 18 uur durende opleiding gehad in de theorie en praktijk van motivational interviewing (MI) en problem solving treatment (PST)., ${ }^{7.8}$ De interventie richtte zich vooral op wat de deelnemers zelf aan hun leefstijl wilden verbeteren. Tevens bespraken de $\mathrm{POH}$ met hen hoe ze een eventuele leefstijlverbetering concreet en stapsgewijs het beste in hun leven konden inpassen. Na maximaal zes begeleidingssessies in hun eigen huisartsenpraktijk kregen de deelnemers gedurende anderhalf jaar driemaandelijkse telefonische sessies. In de procesevaluatie hebben we de kwaliteit van MI en PST beoordeeld met behulp van opgenomen gesprekken en een gevalideerd evaluatie-instrument.

De controlegroep kreeg geen persoonlijke begeleiding, maar ontving alleen brochures van de Hartstichting met informatie over een gezonde leefstijl. Rokers kregen de brochure 'stoppen met roken' van STIVORO.

Na de eerste meting volgden er voor beide groepen nog
Tabel 1 Deelnemerskenmerken van de controle en interventiegroep

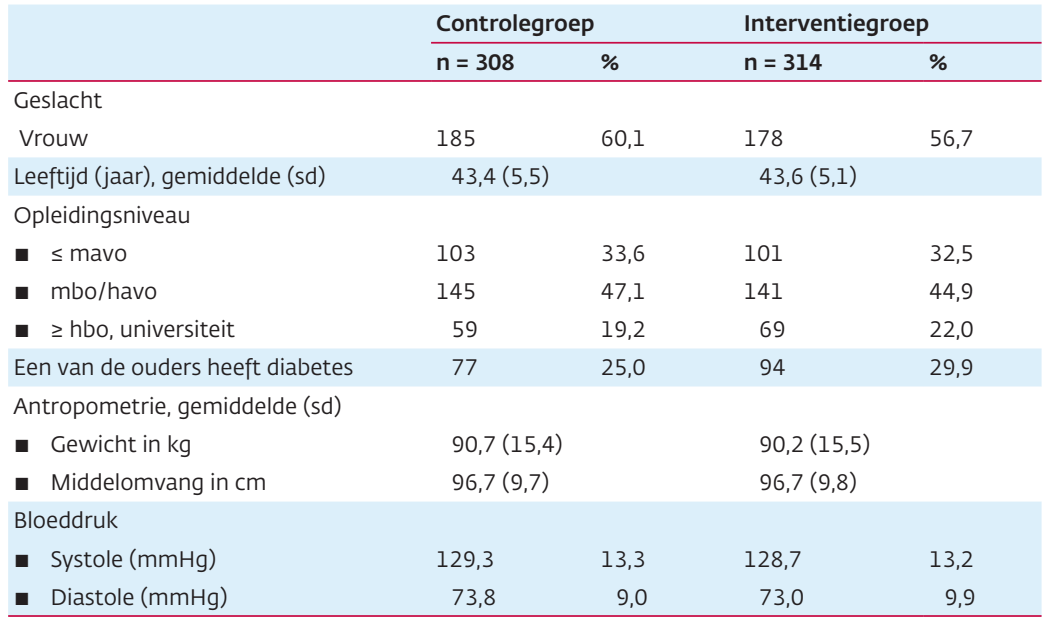

drie follow-upmetingen in het Diabetes Centrum (na 6, 12 en 24 maanden). Voor de economische evaluatie vroegen we de deelnemers tevens om driemaandelijkse kostendagboekjes bij te houden, waarin ze onder andere het zorggebruik, het medicatiegebruik, het productiviteitsverlies en de uitgaven met betrekking tot sport vastlegden.

\section{RESULTATEN}

In totaal hebben 3587 mensen de antwoordkaart teruggestuurd (44\%), van wie er 2401 instemden om mee te doen. Van de 921 personen die daadwerkelijk in aanmerking kwamen op basis van de middelomvang hebben er 772 het Diabetes Centrum bezocht voor de metingen. Uiteindelijk voldeden 622 volwassenen aan alle inclusiecriteria. Zij gaven toestemming en kregen at random een plaats in de controle- of interventiegroep [tabel 1]. Na een half jaar waren er nog 536 deelnemers (86\%), na een jaar 502 (81\%) en na twee jaar 490 (79\%) in het onderzoek.

Intention-to-treatanalyses lieten zien dat er na een half jaar en na een jaar geen verschillen waren in verandering van het risico op DM II of HVZ tussen de groep die persoonlijke begeleiding kreeg van de $\mathrm{POH}$ en de groep die alleen de brochure kreeg. Ook waren er geen statistisch significante verschillen tussen de groepen met betrekking tot verandering van groente- en fruitconsumptie, rookgedrag of lichamelijke activiteit [tabel 2].9 Over het geheel genomen was het leefstijlprogramma dus niet effectiever dan het verstrekken van brochures.

\section{Effectiviteit na twee jaar}

We hebben een economische evaluatie uitgevoerd om de kosteneffectiviteit van het leefstijlprogramma te kunnen beoordelen. Dat hebben we vanuit een maatschappelijk oogpunt gedaan. De resultaten geven aan dat er ook na twee jaar geen significante verschillen zijn tussen de interventie -en controlegroep op het diabetesrisico of op het risico om te overlijden aan HVZ. Er waren ook geen significante verschillen tussen de groepen met betrekking tot het aantal voor kwaliteit gecorrigeerde levensjaren (quality adjusted life years). Het leefstijl- 
Tabel 2 Baseline- en follow-upwaarden, en verschillen tussen de groepen met betrekking tot risicoscores en leefstijlgedrag

\begin{tabular}{|c|c|c|c|c|c|c|c|c|}
\hline & \multicolumn{3}{|l|}{ Controlegroep } & \multicolumn{3}{|c|}{ Interventiegroep } & \multicolumn{2}{|c|}{$\begin{array}{l}\text { Tussengroepsverschillen } \\
(95 \%-\mathrm{BI})\end{array}$} \\
\hline & Baseline & $\begin{array}{l}\text { Follow-up } 1 \\
\text { (6 maanden) }\end{array}$ & $\begin{array}{l}\text { Follow-up } 2 \text { ( } 12 \\
\text { maanden) }\end{array}$ & Baseline & $\begin{array}{l}\text { Follow-up } 1 \\
\text { (6 maanden) }\end{array}$ & $\begin{array}{l}\text { Follow-up } 2 \text { (12 } \\
\text { maanden) }\end{array}$ & Follow-up 1 ( $\beta$ ) & Follow-up 2 ( $\beta$ ) \\
\hline \multicolumn{9}{|l|}{ Risicoscores } \\
\hline - ARIC & $18,8(8,5)$ & $18,0(7,6)$ & $17,8(9,2)$ & $19,0(7,8)$ & $18,8(8,5)$ & $18,5(8,3)$ & $0,4(-0,3-1,0)$ & $0,3(-0,6-1,2)$ \\
\hline - SCORE & $3,8(2,9)$ & $3,7(3,0)$ & $3,7(4,6)$ & $4,0(3,0)$ & $4,0(3,0)$ & $4,0(3,0)$ & $0,0(-0,3-0,2)$ & $-0,2(-0,7-0,4)$ \\
\hline \multicolumn{9}{|l|}{ Lichamelijke activiteit } \\
\hline - licht intensief" & $270(150 ; 371)$ & $296(150 ; 399)$ & $261(137 ; 364)$ & $283(163 ; 392)$ & $274(171 ; 393)$ & $266(171 ; 378)$ & $-13,3(-36,6-10,1)$ & $7,2(-14,5-28,8)$ \\
\hline - matig intensief" & $47(19 ; 120)$ & $47(19 ; 121)$ & $56(26 ; 126)$ & $56(19 ; 150)$ & $47(21 ; 120)$ & $52(21 ; 138)$ & $-9,5(-22,3-3,2)$ & $-9,4(-22,0-3,2)$ \\
\hline - zwaar intensief* & $0(0 ; 17)$ & $6(0 ; 17)$ & $0(0 ; 17)$ & $0(0 ; 17)$ & $0(0 ; 17)$ & $0(0 ; 17)$ & $-0,8(-3,3-1,8)$ & $-0,1(-3,3-3,1)$ \\
\hline - voldoet aan richtlijn NNGB n (\%) $)^{\dagger}$ & $184(59,7)$ & $167(54,2)$ & $160(51,9)$ & $201(64,0)$ & $161(51,3)$ & $162(51,6)$ & OR $0,7(0,5-1,1)$ & OR $0,9(0,6-1,4)$ \\
\hline \multicolumn{9}{|l|}{ Voeding } \\
\hline - stuks fruit per dag & $1,1(0,8)$ & $1,3(1,0)$ & $1,2(0,9)$ & $1,1(0,9)$ & $1,1(0,9)$ & $1,1(0,9)$ & $-0,2(-0,3-0,0)$ & $-0,1(-0,2-0,0)$ \\
\hline - groente-inname (gram per dag) & $150(70,4)$ & $151(68,5)$ & $157(89,9)$ & $148(69,5)$ & $161(126,6)$ & $156(74,6)$ & $9,2(-7,3-25,7)$ & $-0,4(-12,7-11,9)$ \\
\hline
\end{tabular}

Roken

- rokers $\mathrm{n}(\%)$

$54(17,6)$

$46(17,2)$

$43(17,0)$

$74(23,9)$

$53(20,0)$

$46(18,3)$

OR $0,5(0,2-1,9) \quad$ OR $1,1(0,4-3,1)$

De waarden in de tabel zijn gemiddelden (standaarddeviaties), tenzij anders is aangegeven. $\mathrm{BI}=$ betrouwbaarheidsinterval.

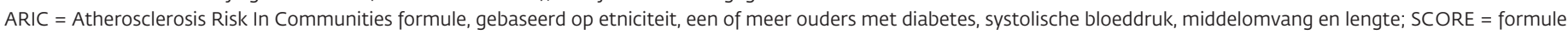
ontwikkeld door de Systematic COronary Risk Evaluation-project, gebaseerd op geslacht, rookgedrag, totaal cholesterol en systolische bloeddruk.

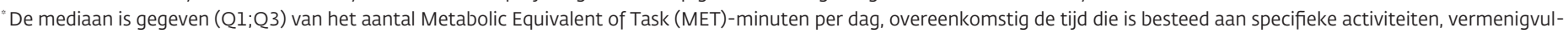

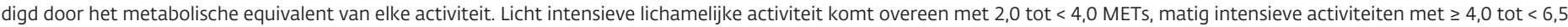
METs, zwaar intensieve lichamelijke activiteit met $\geq 6,5$ METs.

${ }^{\dagger}$ Nederlandse norm gezond bewegen ( $\geq 30$ minuten ten minste matig intensieve lichamelijke activiteit op minimaal vijf dagen van de week).

programma was dus ook na twee jaar niet effectiever dan het verstrekken van een algemene gezondheidsbrochure. Wel was het zo dat diegenen die het leefstijlprogramma hadden gevolgd in vergelijking met de controlegroep iets minder vaak waren opgenomen in het ziekenhuis en relatief minder geld hadden besteed aan gezondheidgerelateerde zaken. Het gemiddelde verschil in totale kosten tussen de interventie- en controlegroep was echter niet statistisch significant ( $€-866$ (95\%-BI -2372 - 370)). We kunnen daarom niet met zekerheid stellen dat deelname aan het leefstijlprogramma de maatschappij een kostenbesparing oplevert. ${ }^{10}$

\section{BESCHOUWING}

In het kader van het Leefstijl Onderzoek West-Friesland hebben we de (kosten)effectiviteit onderzocht van counselinggesprekken die waren uitgevoerd door getrainde $\mathrm{POH}$ in huisartsenpraktijken in Nederland, gericht op leefstijlveranderingen bij volwassenen met een verhoogd risico op DM II en HVZ. Zowel op de korte als de langere termijn maakte het voor het geschatte risico en voor de leefstijl niet uit of men deelnemer was van het leefstijlprogramma of alleen maar een brochure met voorlichtingsmateriaal had gekregen. De interventie is mogelijk op de korte termijn kostenbesparend, maar door de onzekerheden in de schatting van de kosten is het momenteel niet aan te raden om het leefstijlprogramma in te voeren in Nederlandse huisartsenpraktijken.

Het bereik van het programma was goed, de uitval bleek relatief laag en de $\mathrm{POH}$ waren behoorlijk bekwaam in het verstrekken van het cognitieve gedragsprogramma, ${ }^{11}$ maar toch bleek dat het programma niet effectief en niet rendabel was.

De resultaten dragen bij aan de erkenning dat gedragsverandering (en daarmee de afname van chronische ziekten zoals DM II en HVZ) in de huisartsenpraktijk niet effectief kan worden bewerkstelligd met interventies die zich uitsluitend op het individu richten. In toenemende mate gaat men ervan uit dat naast individuele ook omgevingsdeterminanten (de context van de betrokken persoon) een rol spelen bij het teweegbrengen van een duurzame verandering. ${ }^{12}$ of en wanneer mensen bepaalde voedingsmiddelen eten, lichamelijke actief zijn of een sigaret opsteken is niet alleen afhankelijk van individuele keuzen, maar wordt grotendeels beïnvloed door de sociaal-culturele, economische en bebouwde omgevingsfactoren op micro- en macroniveau. De stadsinrichting, sociale netwerken, organisatorische en/of maatschappelijke systemen zijn daarbij mogelijk belangrijke aangrijpingspunten. ${ }^{12}$ Of dit soort geïntegreerde benaderingen de leefstijl van mensen met een verhoogd risico daadwerkelijk duurzaam kunnen veranderen, zal verder onderzoek moeten uitwijzen.

De huisarts blijft in een dergelijke geïntegreerde benadering een belangrijke schakel bij de preventie van DM II en HVZ. Bovendien zal de huisarts hoe dan ook geconfronteerd worden met een groeiend aantal mensen met overgewicht en obesitas, die op enig moment in hun leven professionele hulp zoeken. Pogingen om effectieve interventies te ontwikkelen gericht op het individu zullen daarom praktisch en klinisch relevant blijven, mits ze zijn geïntegreerd in en gecombineerd met een bredere aanpak. Een dergelijke geïntegreerde aanpak vereist samenwerking met disciplines die historisch gezien weinig met leefstijl en gezondheidsuitkomsten van doen hadden, zoals stadsplanologen, architecten, ruimtelijke vormgevers, enzovoort. Het is vooralsnog de vraag welke rol de huisarts zich zou kunnen (of moeten) toe-eigenen bij het faciliteren van die samenwerking, en uiteindelijk van een gezondere omgeving. 


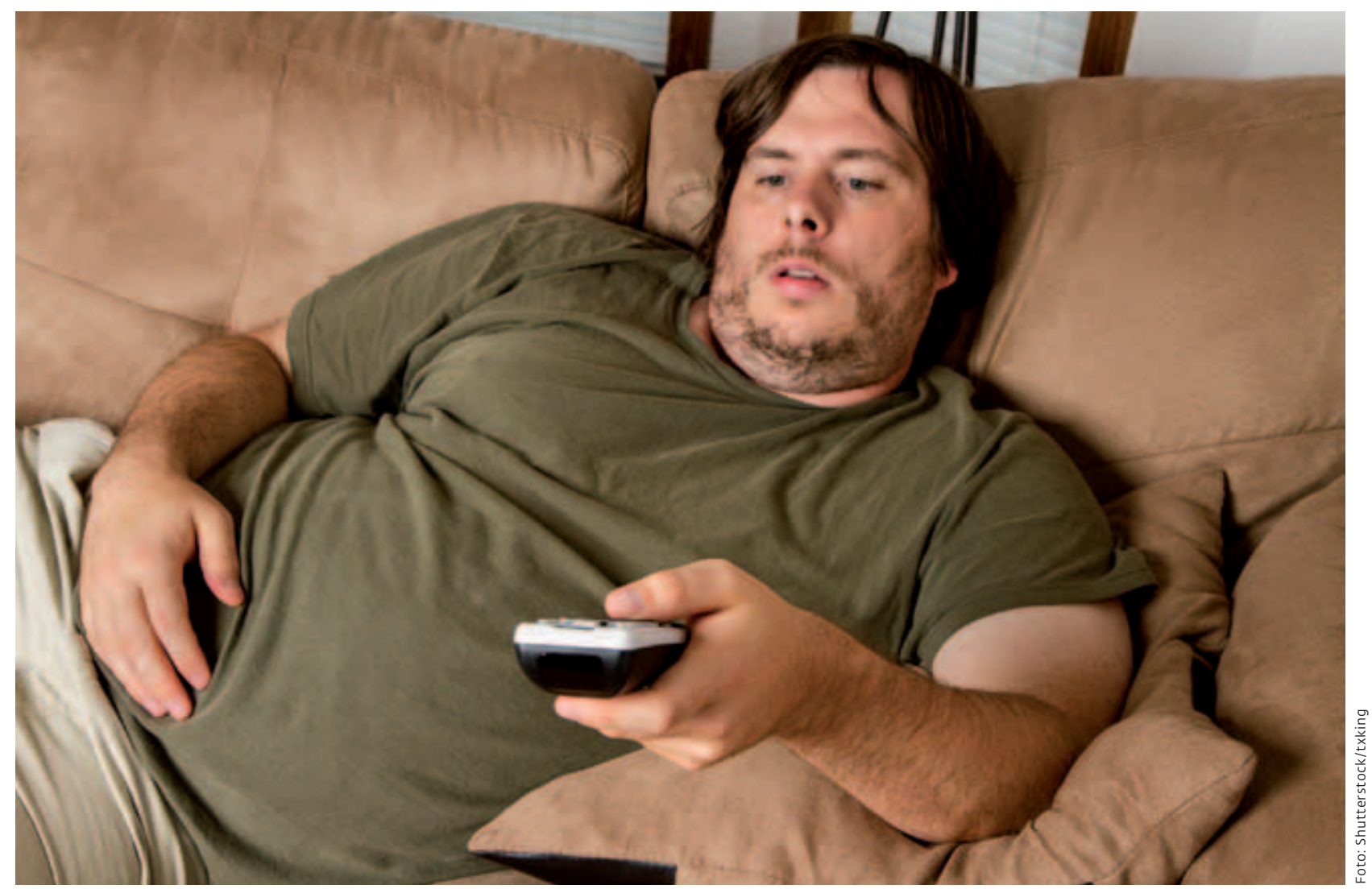

\section{CONCLUSIE}

Ondanks de gunstige resultaten van leefstijlprogramma's op het ontstaan van DM II en HVZ in hooggecontroleerd onderzoek bleek dat het onder voor de huisartsenpraktijk gangbare condities, zowel op de korte als op de langere termijn voor het geschatte risico en voor het leefstijlgedrag niets uitmaakte of patiënten het leefstijlprogramma kregen of alleen maar een brochure met gezondheidsinformatie ontvingen. Leefstijlinterventies zijn mogelijk pas effectief als ze naast individuele determinanten ook aangrijpen op omgevingsdeterminanten. In die zin blijven de individuele interventies relevant, hoewel het momenteel niet is aan te bevelen om de door ons onderzochte interventie in te voeren in Nederlandse huisartsenpraktijken.

\section{LITERATUUR}

1 Gillett M, Royle P, Snaith A, Scotland G, Poobalan A, Imamura M, et al, Non-pharmacological interventions to reduce the risk of diabetes in people with impaired glucose regulation: a systematic review and economic evaluation. Health Technol Assess 2012;16:1-236.

2 Cardona-Morrell M, Rychetnik L, Morrell SL, Espinel PT, Bauman A. Reduction of diabetes risk in routine clinical practice: are physical activity and nutrition interventions feasible and are the outcomes from reference trials replicable? A systematic review and meta-analysis. BMC Public Health 2010;10:653.
3 Lakerveld J, Bot SD, Chinapaw MJ, Van Tulder MW, Van Oppen P, Dekker J, et al. Primary prevention of diabetes mellitus type 2 and cardiovascular diseases using a cognitive behavior program aimed at lifestyle changes in people at risk: design of a randomized controlled trial. BMC Endocr Disord 2008;8:6.

4 Lakerveld J, Bot SD, Chinapaw MJ, Knol DM, De Vet HCW, Nijpels C. Measuring pathways towards a healthier lifestyle: the Determinants of Lifestyle Behavior Questionnaire (DLBQ). Patient Educ Couns 2011;85:e53-8.

5 Schmidt MI, Duncan BB, Bang H, Pankow JS, Ballantyne CM, Colden SH, et al. Identifying individuals at high risk for diabetes: The Atherosclerosis Risk in Communities study. Diabetes Care 2005;28:2013-8.

6 Conroy RM, Pyorala K, Fitzgerald AP, Sans S, Menotti A, De Backer G, et al. Estimation of ten-year risk of fatal cardiovascular disease in Europe: the SCORE project. Eur Heart J 2003;24:987-1003.

7 Miller WR, Rollnick S. Motivational Interviewing: preparing people for change. 2nd ed. New York, London: Guilford Press, 2002.

8 Mynors-Wallis LM. Problem-solving treatment in general psychiatric practice. Adv Psychiatr Treat 2001;7:417-25.

9 Lakerveld J, Bot SD, Chinapaw MJ, Van Tulder MW, Kostense PJ, Dekker JM, et al. Motivational interviewing and problem solving treatment to reduce type 2 diabetes and cardiovascular disease risk in real life: a randomized controlled trial. Int J Behav Nutr Phys Act 2013;10:47.

10 Van Wier MF, Lakerveld J, Bot SD, Chinapaw MJ, Nijpels G, Van Tulder MW. Economic evaluation of a lifestyle intervention in primary care to prevent type 2 diabetes mellitus and cardiovascular diseases: a randomized controlled trial. BMC Fam Pract 20134:14:45.

11 Lakerveld J, Bot S, Chinapaw MJ, Van Tulder MW, Kingo L, Nijpels G. Pro cess evaluation of a lifestyle intervention to prevent diabetes and cardiovascular diseases in primary care. Health Promot Pract 2012 Jul 6;13:696706.

12 Lakerveld J, Brug J, Bot SD, Teixeira P, Rutter H, Woodward E, et al. Sustainable prevention of obesity through integrated strategies: The SPOTLICHT project's conceptual framework and design. BMC Public Health 2012;12:793. 